\title{
Isolation, characterization and storage of probiotics associated with the fermentation of Bambara groundnut bran
}

\begin{abstract}
The research was carried out to isolate, characterize, and store lactic acid bacteria (LAB) from bambara groundnut bran. The debranned Bambara groundnut were fermented for four days, and TTA (Total Titrable Acidity), $\mathrm{pH}$ and microbial load determination were carried out for every 24 hours of fermentation. Eighteen acid-producing cultures were isolated from these samples, and isolates were divided into classes first by phenotype. Phenotypic and biochemical characteristics led to identification of seven bacterial groups (1 to 7). Lactobacillus plantarum was the most abundant type of LAB distributed in the isolates of fermented bambara groundnut bran, followed by Lactobacillus acidophilus which was the most abundant LAB found in two of the isolates and Lactobacillus esenteroides was found in the remaining two isolates. These results suggest that various LAB are distributed in bambara groundnut bran and L. plantarum was the most abundant LAB found in this study. The microorganisms isolated were then freeze dried using a freeze drier and then kept at a low temperature in the refrigerator so as to preserve/store the organisms for further processes. This report thereby shows that bambara groundnut bran can be used for neutraceutics instead of disposing them as waste.
\end{abstract}

Volume 8 Issue 6 - 2018

\author{
Adeoye BK, Obayemi MO,Akinola SA \\ Department of Food Science and Technology, Federal University \\ of Technology, Nigeria
}

Correspondence: Adeoye BK, Department of Food Science and Technology, Federal University of Technology, Akure, Ondo State, Nigeria, Email chembebs2007@yahoo.com

Received: May 15, 2018 | Published: November 26, 2018

Keywords: bambara groundnut, bran, lactic acid, bacteria, fermentation, isolate

\section{Introduction}

Isolation refers to the separation of a strain from a natural, mixed population of living microbes as present in the environment. ${ }^{1}$ Bacterial isolation, purification and identification are the first steps to bacteriological studies. Isolation is done to obtain pure bacterial cultures. Pure culture is essential in the study of the morphology, physiology, biochemical characteristics, and susceptibility to antimicrobial agents of a particular bacterial strain. ${ }^{1}$ The formulation of the dietary supplements, functional foods or herbal products into marketed medicinal products is known as "nutraceuticals"; a term which combines "nutrition" and "pharmaceuticals". Among various nutraceuticals of major importance in diseases prevention is probiotics. ${ }^{3}$ Probiotics are live microorganisms which when administered in adequate amounts confer a beneficial health benefit on the host. ${ }^{4}$ Probiotics can be delivered commercially either as nutritional supplements, pharmaceuticals or foods. A large number of probiotic products are available in the market in the form of milk, drinking and frozen yoghurts, probiotic cheeses, ice creams, dairy spreads and fermented soya products. Also, special freeze-dried pharmaceutical dietary preparations are available in the form of tablets. ${ }^{5}$ Together with prebiotics, probiotics are often consumed as functional foods, demonstrated to be effective for the treatment or control of several diseases. Prebiotic substances, such as lactulose, lactitol, xylitol, inulin and certain non-digestive oligosaccharides, selectively stimulate the growth and activity of, for example, bifidobacteria in the colon (Zubillaga and Roberfroid, 2010). Most widely and commercially used probiotic species are Lactobacillus (L. acidophillus, L. casei, L. fermentum, L. gasseri, L. johnsnli, L.lactis, L. paracasei, L. plantarum, L. reuteri, L. rhamnosus, L. salivarius), Bifidobacterium(B. bifidum, $B$. breve, B. lactis, B. longum), Streptoccocus(S. thermophilus) species, yeasts and molds (Saccharomyces boulardii).

Probiotic microorganisms have been studied as successful ingredients in functional food segment. The popularity of probiotic foods is due to its numerous health benefit attributes to it intake. ${ }^{6}$ A number of health benefit of probiotic products have been proposed including antimicrobial, antimutagenic, anticarcinogenic, antihypertensive properties, reduction of allergic symptoms, reduction of diarrhea and stimulation of the immune system..$^{7-10}$ To achieve the benefit from their injection, the probiotics microorganisms must reach the intestine alive and in sufficient concentration, surviving the harsh conditions found during the flow through the gastrointestinal tract (Hassan, et al., 2012). A minimum daily intake of 8.9 log of colony forming unit (CFU) or 6-7 log cfu/g or $1 \mathrm{ml}$ of food is generally recommended. ${ }^{11}$ The survival of probiotic microorganisms in food products is strongly influenced by $\mathrm{pH}$ and post-acidification, which may occur during refrigerated storage of fermented products. Other factors such as production of hydrogen peroxide, oxygen level, temperature and food matrix also affect the microbial viability. ${ }^{12}$

Probiotics have been used for centuries in food fermentation and dairy products are the main carriers of probiotic bacteria to human, as these products provide a suitable environment for probiotic bacteria that support their growth and viability. ${ }^{13}$ The world-wide probiotic foods are milk based and very few attempts are made for the development of probiotic foods using other fermentation substrates such as legumes. With an increase in the consumer vegetarianism in the developing countries coupled with the low purchasing power of low income people especially in sub-Sahara Africa to consume much dairy product needed for probiotics, there is also a demand for the vegetarian probiotic products. Nondairy probiotic products have shown a big interest among vegetarians and lactose intolerance customers. A potential sources of vegetarian probiotics are legumes due their large distribution and important nutritive value. Bambara groundnut (Vigna subterranean) is an indigenous African crop known to have been domesticated in West Africa from its presumed wild ancestor (Ferry, 2002). Bambara groundnut contains about $61.3 \%$ carbohydrate, $20.7 \%$ protein and $6.0 \%$ oil,${ }^{14}$ and is used as main food, 
snacks, relish and medicine, and has high ceremonial value. ${ }^{15}$ Despite its high and balanced protein content, Bambara groundnut remains under-utilized because it takes a long time to cook and contains antinutritional factors such as tannins and trypsin inhibitors, and it has poor milling characteristics, as it does not dehull easily. ${ }^{16}$

In order to maximize the utilization of the Bambara groundnut, the bran was then subjected to fermentation process to enhance the quality parameters and functional properties of the raw material. Fermentation with well-characterized starter cultures, yeast or Lactic Acid Bacteria (LAB), is a potential means to improve the palatability and process ability of brans and whole-meal flours. ${ }^{17}$ Furthermore, bran fermentation could assist in the management of indigenous microbes and improvement of the microbiological safety of bran. Therefore, this research was carried out to isolate, characterize and store Lactic Acid Bacteria from the bran of Bambara groundnut instead of disposing it as waste.

\section{Materials and methods}

Dried Bambara groundnut was obtained from Institute of Tropical Agriculture, Ibadan, Nigeria. The cleaned sample of Bambara groundnut was de-branned by removing the outer part of the legume. This was done by soaking the seed in water for 30 minutes to enable easy removal of the seed coat which was done manually.

\section{Bran fermentation}

$45 \mathrm{~g}$ of the powdered bran was measured using an analytical balance into a sterile container and was mixed with $200 \mathrm{ml}$ of distilled water and the sterile container was covered, this was done in four different sterile container to allow fermentation to be done for 4days ( $24 \mathrm{hr}$ at 20 or $32^{\circ} \mathrm{C}$ for each container). Spontaneous fermentations were carried out. Fresh samples were taken from each fermented bran for microbiological analyses. In addition, samples were also taken for later measurements of $\mathrm{pH}$ and total titratable acidity (TTA) and fermented bran samples were later freeze-dried for analysis of bioactive compounds. Fermentations were done in duplicate and performed twice (four times altogether) (Figure 1)

\section{Determination of $\mathrm{pH}$}

The $\mathrm{pH}$ meter was first calibrated using buffer solution of $\mathrm{pH} 4$ and $\mathrm{pH} 7$ in order to determine the accuracy of the $\mathrm{pH}$ meter to be used. $90 \mathrm{ml}$ of the fermented substrate was measured into a beaker and $10 \mathrm{ml}$ of distilled water was added to it, the $\mathrm{pH}$ meter was dipped into the measured substrate, switched on and allowed to be stabilized before the result displayed on the meter was taken and recorded. ${ }^{18}$

\section{Determination of total titratable acidity (TTA)}

This was done by the methods described by Antony and Chandra, $1997^{19}$ which was later modified by Ferrati et al. ${ }^{20}$ The burette was rinsed and set up on the retort stand and fixed tightly and carefully. $10 \mathrm{mls}$ of the fermented substrate was measure into a conical flask and $90 \mathrm{ml}$ of distilled water was added to it. $0.1 \mathrm{M} \mathrm{NaOH}$ was run into the burette to fill the burette to any mark, 2 drops of phenolphthalein indicator were carefully dropped into the substrate in the beaker and shaken. The initial volume of the alkaline in the burette was noted. The alkali was run briskly into the beaker containing the substrate and indicator which was consistently shaken until there was a sharp change of the substrate to pink. The volume of the alkali in the burette at this point was noted to enable the determination of the volume of base (titre value of alkali) used. TTA was expressed as the amount of $\mathrm{NaOH}$ used (ml).

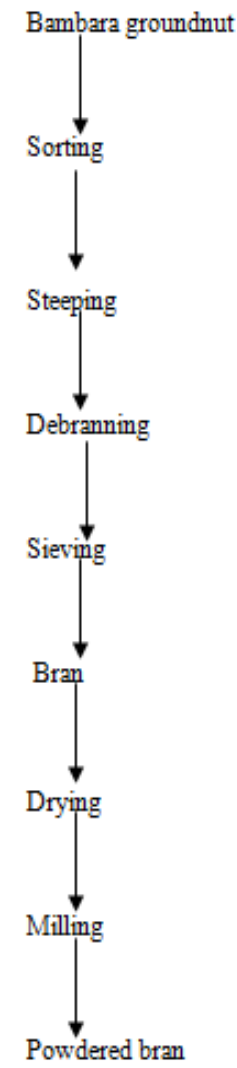

Figure I Flowchart showing the debranning of Bambara Groundnut Analysis

\section{Preparation of culture media and diluent}

The culture media, each in the powdered form were reconstituted with distilled water according to the manufacturers' instructions. Proper dissolution was achieved by placing the flask in a hot plate at $50^{\circ} \mathrm{C}$ for $4 \mathrm{~min}$. They were sterilized by autoclaving at $121^{\circ} \mathrm{C}$ and $15 \mathrm{mmHg}$ for 15 minutes and cooled to $45^{\circ} \mathrm{C}$ before dispensing into sterile Petri dishes and left to gel. The diluent was prepared by adding $0.85 \mathrm{~g} \mathrm{NaCl}$ to $100 \mathrm{ml}$ of distilled water and $9 \mathrm{ml}$ each was measured into dilution bottles which were covered tightly and sterilized in an autoclave at $121^{\circ} \mathrm{C}$ and $15 \mathrm{mmHg}$ for 15 minutes and cooled to $45^{\circ} \mathrm{C}$.

\section{Isolation of microorganisms}

Isolation of microorganisms was done by method described by Harrigan and $\mathrm{McCance}{ }^{21}$ After sterilization of agars and diluents, the workbenches were sterilized using ethanol and cotton wool and a spirit lamp was lighted, placed on the work bench to create an aseptic environment. The sterile Petri dishes were arranged and labeled on the sterilized work bench, the cooled dilution bottles were also placed on the work bench and serial dilution was done at 3-fold dilutions $\left(10^{0}, 10^{-1}, 10^{-2}\right.$, and $\left.10^{-3}\right) .1 \mathrm{ml}$ of dilution factor $10^{-2}$ was inoculated via pour plate method on MRS agar by adding $0.3 \mathrm{ml}$ of lactic acid. The Petri dishes containing the substrate and medium were incubated in an anaerobic jar which was put into an incubator at $37^{\circ} \mathrm{C}$ for 48 hours. Discrete colonies from each plate were sub cultured. The pure isolates gotten were preserved in a prepared broth bottle containing nutrient agar before biochemical tests were further carried out. 


\section{Identification and characterization of isolates}

Colonies were selected randomly and were characterized using morphological characterization and biochemical tests such as gram stain, catalase, and sugar fermentation tests. Bacterial isolates were identified with reference to Cowan and Steel's Manual for the Identification of Medical bacteria (Cowan, 1985) and Bergey's manual of determinative Bacteriology. ${ }^{22}$ The bacterial isolates identification was based on colony morphology, cultural characteristics and biochemical tests using the methods described by Cheesebrough. ${ }^{23}$

\section{Morphological characterization}

The Morphological characterization observed include the shape, colour, size and surface.

\section{Biochemical characterization}

Distinct pure colonies observed to be dominant were checked for gram reactions using microscopic examination for cell morphology.

\section{Gram stain}

The method used was that described by Harrigan and $\mathrm{McCance}^{24}$ A smear of the test organism was made on a grease free glass slide and heat fixed. The smear was stained with crystal violet for 1 minute, rinsed with water and excess water was drained off. The slide was flooded with lugol's iodine for 1minute and it was rinsed with running water. The smear was decolorized with absolute alcohol over it until blue colouration ceased to leave the smear, it was rinsed immediately with water and drained off excess water for 5-10 seconds. The slide was counterstained with $0.5 \%$ safranin for 1 minute, the slide was rinsed with water and allowed to dry. Immersion oil was added and was observed under the microscope using the oil immersion(x100) objective lens. Gram positive bacteria retained the colour of the primary stain which is purple. Gram negative bacteria take the colour of the counter stain (safranin, neutral red, dilute carbolfuchsin) which is red or pink.

\section{Spore stain}

The malachite green staining method was used. The staining was carried out as described by Harrigan and $\mathrm{McCance}^{24}$ Smears of the pure isolates were made on grease-free glass slide and heat fixed. The slides were flooded with $5 \% \mathrm{v} / \mathrm{v}$ malachite green solution. The slides were flamed in such a way that the stain steamed but did not boil. The slides were then allowed to stand for 5 minutes. The stain was then washed out in running tap water. The smears were counter stained with saffranin for 30 seconds. This was stained with saffranin for were blotted, dried and examined under the oil immersion objective. The spores stained green while vegetative cells stained red.

\section{Motility test}

This test was used to determine if the isolates were motile. Motility test is usually used to differentiate motile organisms from non-motile ones. For this test, the hanging drop technique was employed and the technique was carried out as described by Harrigan and $\mathrm{McCance}^{24}$ Vaseline jelly was rubbed around the cavity of a hanging drop slide. A drop of peptone water containing the pure culture was placed on a cover slip. The hanging drops slide was then placed over the drop of peptone water in such a way that the center of the depression lies over the drop. The slide was quickly inverted and viewed under the microscope, using oil immersion objective.

\section{Catalase test}

This test was used to demonstrate which of the isolates could produce the enzyme catalase that release oxygen from hydrogen peroxide. This test is usually used to differentiate other catalase positive organism from catalase negative (Barker, 1976). The method employed here was that described by Jagbir ${ }^{25}$ A loop of the pure colony was transferred into a plain, clean glass slide. The sample was then mixed with a drop of $3 \% \mathrm{v} / \mathrm{v}$ hydrogen peroxide. It was observed for effervescence, immediate bubbling indicates that the organism is catalase positive.

\section{Sugar fermentation test}

Each of the isolates was tested for its ability to ferment a given sugar with the production of acid and gas or acid only. Since most bacteria especially Gram negative bacteria utilize different sugars as source of carbon and energy with the production of both acid and gas, or acid only the test is used as an aid in their differentiation. The growth medium used was peptone water and the method used was that described by Grujot ${ }^{26}$ Peptone water was prepared in a conical flask and the indicators phenol red was added. The mixture was dispensed into test tubes containing Durham tubes. The tubes with their content were sterilized by autoclaving at $121^{\circ} \mathrm{C}$ for 15 minutes. $1 \%$ solution of the sugar was prepared and sterilized separately at $115^{\circ} \mathrm{C}$ for 10 minutes. This was then aseptically dispensed in $5 \mathrm{ml}$ aliquot volume into the tubes containing the peptone water and indicator. The tubes were inoculated with young culture of the isolates and incubated at $37^{\circ} \mathrm{C}$. Acid and gas production or acid only were observed after about 24 hours of incubation. Acid production was indicated by the change of the medium from pale red to yellow colour, while gas production was indicated by the presence of gas in the Durham's tubes. The control tubes were not incubated Prescott et al. ${ }^{27}$

\section{Preparation of Fresh Broth and Freeze Drying}

After biochemical test, the pure isolates gotten were sub cultured in a fresh prepared broth (according to the manufacturer's instructions) bottle containing nutrient agar and was incubated at $37^{\circ} \mathrm{C}$ for 24 hours. After incubation, the sample bottles containing broth and the bacteria were transferred into a freezer to freeze and then loaded in a freeze drier for proper and complete drying. This was done by the method described by Oetjen et al. ${ }^{28}$ The samples were frozen below the critical temperature of the formulation and were then followed by primary drying, where the chamber pressure was lowered, the shelf temperature usually increased and the unbound water removed by sublimation. Finally, a secondary drying step was done to remove the bound water by desorption and the samples were gradually brought back to ambient temperature (Figure 2).

\section{Results and discussion}

\section{Determination of $\mathrm{pH}$, total titrable acidity (TTA) and microbial load}

For $\mathrm{pH}$, there is increment in the $\mathrm{pH}$ level as the fermentation days increases and the TTA also increases as the fermentation days increases. One hundred and twelve (112) LAB colonies were isolated from the spontaneous fermentations in all the plates for 4 days (in duplicates each day), 45 colonies for day 1, 35 colonies for day 2 , 25 colonies for day 3 and 12 colonies for day 4 . The result is being represented in Table 1. 


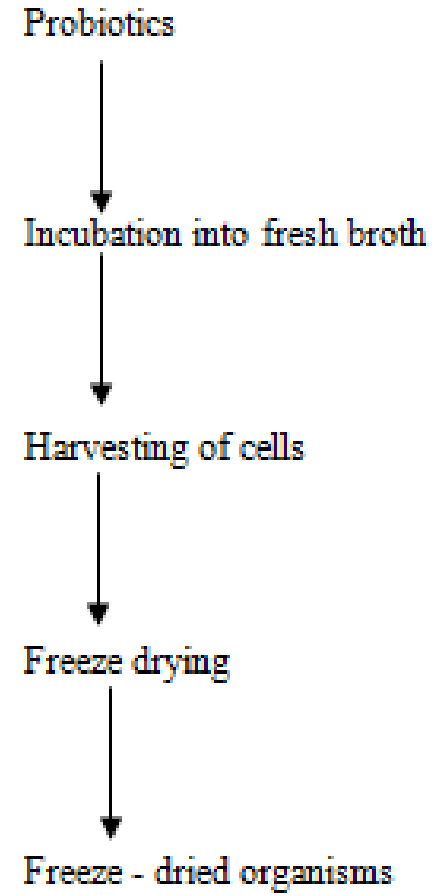

Figure 2 Flowchart showing the processing of freeze-dried organisms. Table I pH,TTA and microbial results during fermentation for 4days

\begin{tabular}{lllll}
\hline Analysis & BGB I & BGB 2 & BGB 3 & BGB 4 \\
\hline $\mathrm{pH}$ & 2.94 & 4.50 & 6.01 & 6.11 \\
TTA & $0.012 \%$ & $0.011 \%$ & $0.008 \%$ & $0.0088 \%$ \\
Microbial load & 45 & 35 & 20 & 12 \\
\hline
\end{tabular}

\section{KEYS}

BGB I: Bambara Groundnut Bran in sterile container at 24hours

BGB 2: Bambara Groundnut Bran in sterile container at 48 hours

BGB 3: Bambara Groundnut Bran in sterile container at 72 hours

BGB 4: Bambara Groundnut Bran in sterile container at 96 hours

\section{Identification on Isolates}

Each of the isolates was subjected to Gram stain test and were examined under light microscope. Each of the isolates (7 from MRS) gave blue-purple color with staining; hence they all were Gram positive bacteria. The isolates from MRS plates were rod-like bacilli with long or rounded ends. Spore staining and motility test were negative for all isolates both on the MRS plates and NA plates. This implies none of the isolates formed spores and are non-motile. All of the isolates both on MRS and NA plates were tested for catalase. None of them showed catalase activity. This showed that they are catalase negative. On MRS plate for gas production, isolate 1 was negative for Glucose, Fructose, Lactose, Sucrose and Mannitol. Isolate 2 was negative for Fructose, Maltose, Sucrose and Mannitol. Isolate 3 was negative for Glucose, Fructose, Maltose, Lactose, Sucrose and Mannitol. Isolate 4 was negative for Mannitol only. Isolate 5 was negative for Glucose, Fructose, Maltose, Sucrose and Mannitol. Isolate 6 was negative for Glucose and Mannitol only.

For acid production, Isolate 1 was negative for Glucose, Sucrose and Mannitol. Isolate 2 was negative for none of the sugars. Isolate 3 was negative for Glucose, Fructose, Maltose, Lactose, Sucrose and Mannitol. Isolate 4 was negative for none of the sugars. Isolate 5 was negative for Glucose, Fructose, Maltose, Lactose, Sucrose and Mannitol. Isolate 6 was negative for Fructose, Maltose, Lactose and Mannitol. Isolate 7 was negative for Mannitol only. The results are shown in Table $2-4$

Table 2 Morphological characteristics of isolated organism

\begin{tabular}{ll}
\hline Morphological characteristics & Probable organisms \\
\hline Purple, very short rod, irregular shape & Lacobacillus mesenteroides \\
Purple, short rod, regular shape & Lacobacillu splantarum \\
Purple, long rod, regular shape & Lactobacillus acidophilus \\
Purple, short rod, regular shape & Lactobacillus plantarum \\
Purple, short rod, regular shape & Lactobacillus plantarum \\
Purple, short rod, irregular shape & Lactobacillus mensenteroides \\
Purple, long rod, regular shape & Lactobacillus acidophilus
\end{tabular}

Table 3 Biochemical identification result for isolates on MRS plates

\begin{tabular}{llllllll}
\hline Biochemical Identification & Isolate I & Isolate $\mathbf{2}$ & Isolate $\mathbf{3}$ & Isolate $\mathbf{4}$ & Isolate $\mathbf{5}$ & Isolate $\mathbf{6}$ & Isolate $\mathbf{7}$ \\
\hline $\begin{array}{l}\text { Morphology } \\
\text { Gram stain }\end{array}$ & Bacilli & Bacilli & Bacilli & Bacilli & Bacilli & Bacilli & Bacilli \\
Spore stain & Positive & Positive & Positive & Positive & Positive & Positive & Positive \\
Motility test & Negative & Negative & Negative & Negative & Negative & Negative & Negative \\
Catalase test & Negative & Negative & Negative & Negative & Negative & Negative & Negative \\
\hline
\end{tabular}

\section{Conclusion}

In this research, Lactic Acid Bacteria (LAB) was isolated, characterized, identified and stored from spontaneously fermented bambara groundnut bran. The results obtained shows that microorganisms associated with the fermented bambara groundnut bran are bacteria that are probiotics which can beneficial to human and can then be used for neutraceutics in the production of encapsulated products for the enhancement of immune system and proper functioning of the human GIT (Gastro Intestinal Tract). 
Table 4 Carbohydrate fermentation result for isolates on MRS plates

\begin{tabular}{|c|c|c|c|c|c|c|c|}
\hline Carbohydrates Fermentation & Isolate I & Isolate 2 & Isolate 3 & Isolate 4 & Isolate 5 & Isolate 6 & Isolate 7 \\
\hline \multirow[t]{2}{*}{ Glucose } & - & $\mathrm{Gb}$ & - & $\mathrm{Gb}$ & - & - & - \\
\hline & - & As & - & As & - & As & $A b$ \\
\hline \multirow[t]{2}{*}{ Fructose } & - & - & - & $\mathrm{Gb}$ & - & - & Gs \\
\hline & As & As & - & $A b$ & - & - & $A b$ \\
\hline \multirow[t]{2}{*}{ Maltose } & - & - & - & $\mathrm{Gb}$ & - & - & $\mathrm{Gb}$ \\
\hline & As & - & - & $\mathrm{Ab}$ & - & - & $\mathrm{Ab}$ \\
\hline \multirow[t]{2}{*}{ Lactose } & - & Gs & - & Gs & - & - & Gs \\
\hline & As & As & - & As & - & - & $\mathrm{Ab}$ \\
\hline \multirow[t]{2}{*}{ Sucrose } & - & - & - & $\mathrm{Gb}$ & - & - & Gs \\
\hline & - & - & - & $\mathrm{Ab}$ & - & As & As \\
\hline \multirow[t]{2}{*}{ Mannitol } & - & - & - & - & - & - & - \\
\hline & - & As & - & As & - & - & - \\
\hline
\end{tabular}

KEYS

- , negative to the test

Gb, gas (Durham tube more than $1 / 4$ full)

$\mathrm{Ab}$, acid, full color change Gs, slight gas (Durham tube less than $1 / 4$ full)

As, small amount of acid i.e indicator not fully changed in colour

\section{Acknowledgements}

None.

\section{Conflicts of interest}

The authors declare that there is no conflicts of interest.

\section{References}

1. Elizete DF, Carlos SR. Biochemical characterization and identification of probiotic Lactobacillus casei from various foods. Journal of Biology. 2005;30:39-44.

2. Noha ZM. Progress and Problems in Nutraceuticals Delivery Bioequivalence and Bioavailability. 2013;6(3):75-77.

3. Smith J, Charter E. Functional Food Product Development Charlottetown: John Wiley and Sons Ltd. 2010.

4. CM Kalui, JM Mathara, PM Kutima. Probiotic potential of spontaneously fermented cereal based foods. African Journal of Biotechnology. 2010;9(17):2490-2498

5. Food and Agriculture Organization/World Health Organization. Guidelines for the Evaluation of Probiotics in Food: Report of a Joint FAO/WHO Working Group on Drafting Guidelines for the Evaluation of Probiotics in Food; London, Ontario, Canada, FAO/WHO. 2002.

6. Ohshi Y, Ushida K. Health beneficial effects of probiotics: its mode of action. Animal science Journal. 2009;80(4):361-371.

7. Scheinbach S. Probiotics: Functionality and commercial status. Biotech Adv. 1998;16(3):581-608.

8. Shah NP. Some beneficial effect of probiotic bacteria. Bioscience microflora. 2000;19(2):99-106.

9. Lourens-Hattingh A, Viljoen BC. Yogurt as probiotics carrier food. International Dairy Journal. 2001;1:11-17.
10. Schrezenmier J, De Vrese M. Probiotics, prebiotics and synbioticsApproaching a definition. Am J Clin Nutr. 2001;73(2 Suppl):361S-346S

11. Cruz AG, Antunes AEC, Sousa ALOP, et al. Ice-cream as a probiotic food carrier. Food Resources International. 2009;42(9):1233-1239.

12. Dave RI, Shah NP. Viability of yoghurt and probiotic bacteria in yoghurts made from commercial starter culture. International Dairy Journal. 1997;7(1):31-41.

13. Fernanda HB, Diab R, Andreea P. Encapsulation of probiotics: insights into academic and industrial approaches. AIMS Materials Science. 2016;136-144.

14. Yusuf AA, Ayedun H, Sanni LO. Chemical composition and functional properties of raw and roasted Bambara groundnt (Vignasubterranea). Journal of Food Chemistry. 2008;111(2):277-282.

15. Oluwole FA, Abdulrahim AT, Olaler RK. Effect of moisture content on crackability of bambara groundnut on composite flour using a centrifugal cracker. International Agrophysics. 2007;21:179-184.

16. Barimalaa IS, Anoghalu SC, Idisi Yibatama, et al. Studies on the solid of substrates fermentation of bambara groundnut (Vigna subterranean (L.) Verde). Journal of Science Food Agriculture. 1997;66:443-446.

17. Salmenkallio-Marttila M, Katina K, Autio K. Effects ofbran fermentation on quality and microstructure of high-fiber wheatbread. Cereal Journal of Food Chemistry. 2001;78:429-435.

18. AOAC. Official Methods of Analysis of AOAC International. 18 $8^{\text {th }} \mathrm{ed}$, AOAC International, Gaithersburg. MD., United State of American. 2005. ISBN - 13:978-0935584752.

19. Anthony U, Chandra TS. Microbial population and biochemical changes in fermenting finger millet. World Journal Microbiology Biotechnology. 1997;13(5):533-537.

20. Ferrati AR, Tavolaro MT, Destro M, et al. A comparison of ready - to - use systems for evaluating the microbiological quality of acidic foods 
using experimental models. Int Microbiol. 2005;8(1):49-53.

21. Harrigan WF, McCance ME. Laboratory Methods in Microbiology, Academic press, London and New York. 1976.

22. Holt JG. Bergey's manual of Systematic Bacteriology. Lippincott Williams and Wikkins Limited., Baltimore. 1994;787.

23. Cheesebrough M. District Laboratory Practice in Tropical Countries, Part 2. Cambridge University Press, Cambridge, United Kingdom. ISBN - 2006;13:9780521665452.

24. Harrigan WF, McCance ME. Laboratory Methods in Food and Dairy Microbiology, $8^{\text {th }}$ ed. Academic press, London. 1990.
25. Jagbir SN. Isolation and characterization of Staphylococcus aureus from pooled milk samples of local dairies. M.Sc. Thesis (Published). Punjab Agricultural University, Ludhiana.2011.

26. Gurjot $\mathrm{K}$ Isolation and characterization of endophytic bacteria from rice (Oryza sativa L.). M.Sc. Thesis (Published). Punjab Agricultural University, Ludhiana. 2016.

27. Prescott ML, Harley JP, Klen DA. General Microbiology. McGrawHill. 2008.

28. Oetjen L, Haseley M, Klitsch K, et al. Method for controlling a freeze drying process. United States Patent. 2000;6:163-979. 